\title{
Building Resilience in a Major City Evacuation Plan Using Simulation Modeling
}

\author{
Adam Kirby, J. Eric Dietz, and Eric Matson \\ Computer and Information Technology, Purdue University \\ Joseph Pekny \\ Chemical Engineering, Purdue University \\ Clifford Wojtalewic \\ Purdue Homeland Security Institute, Purdue University
}

\begin{abstract}
This study provides data on the optimal staff, materials, space, and time resources required to operate a regional hub reception center, a "short-term facility with the goal to process and transport displaced survivors (evacuees) to temporary or permanent shelters following a catastrophic incident" (Regional Catastrophic Planning Team, 2012). The facility will process approximately 20,000 evacuees over its entire 7-day duration following a disaster to assist in community resilience. The study was performed using a model created using the computer simulation software, AnyLogic. The results of the study demonstrated that the goals set forth by the Illinois-Indiana-Wisconsin Regional Catastrophic Planning Team could be improved upon and that the largest contributing factor to optimizing the RHRC is finding the optimal number of total staff members to operate the facility.
\end{abstract}

Keywords: agent-based, AnyLogic, carless population, discrete event, modeling, resilience, RHRC, simulation

\section{INTRODUCTION}

Disaster, whether man-made or natural, can have a catastrophic impact on a populated area. Sometimes, the disaster is so devastating that it requires a largescale evacuation. As a result, evacuation plans have become a necessity. One such evacuation plan is the regional hub reception center (RHRC), which will help to evacuate the carless population when an evacuation is needed. The carless population is defined as "those without access to cars or those without the physical or economic means to evacuate" (Renne, Sanchez, Jenkins, \& Peterson, 2009). Using a simulation modeling software called AnyLogic, an RHRC model was developed to test the efficiency of the proposed plan. Since the RHRC could be a major tool used in future disasters, a study had to be performed to find the optimal amounts of staff, materials, space, and time needed for the facility to perform all of its necessary functions. A sample RHRC layout can be seen in Figure 1. The Regional Catastrophic Planning Team hopes that a single RHRC can process 20,000 evacuees in 7 days with each evacuee staying in the facility for less than 24 hours (Regional Catastrophic Planning Team, 2012).

In this research, a hybrid discrete event agent-based model was created within AnyLogic. The assumptions for the model were taken from the Illinois-IndianaWisconsin Regional Catastrophic Planning Team's Regional Hub Reception Center-Operational Guidance document. The most important resource being optimized was staff. The predetermined staffing allocation is shown in Table 1.

A previous study was performed to determine the average individual throughput time for individuals in the RHRC based on the staffing numbers shown in Table 1. The result was 1.05 days per person. The entire process also took 7.49 days on average and did not account for the capacity of the facility. The results of the study were determined to be slightly above the Regional Catastrophic Planning Team's goals, but close enough to be acceptable. However, further research was required for optimization (Kirby, Dietz, \& Wojtalewicz, 2012).

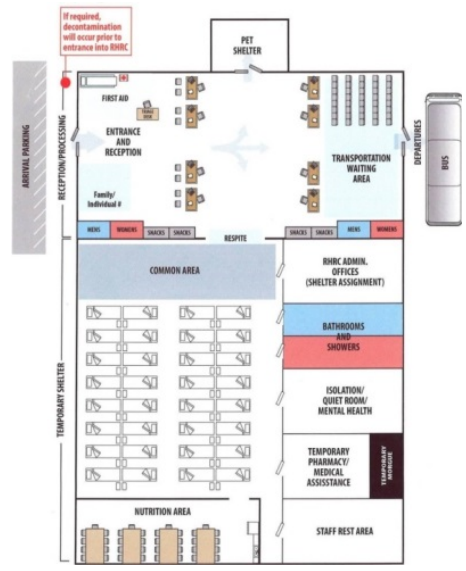

Figure 1. RHRC layout 
Table 1. Predetermined staffing allocation

\begin{tabular}{|c|c|}
\hline Position & Number of Staff \\
\hline Decontamination staff & 20 \\
\hline Pet registration staff & 72 \\
\hline Registration staff & 72 \\
\hline Assessment staff & 12 \\
\hline Medical care staff & 60 \\
\hline Mental care staff & 29 \\
\hline Food staff & 36 \\
\hline Shelter assignment staff & 15 \\
\hline Total staff & $\mathbf{3 1 6}$ \\
\hline
\end{tabular}

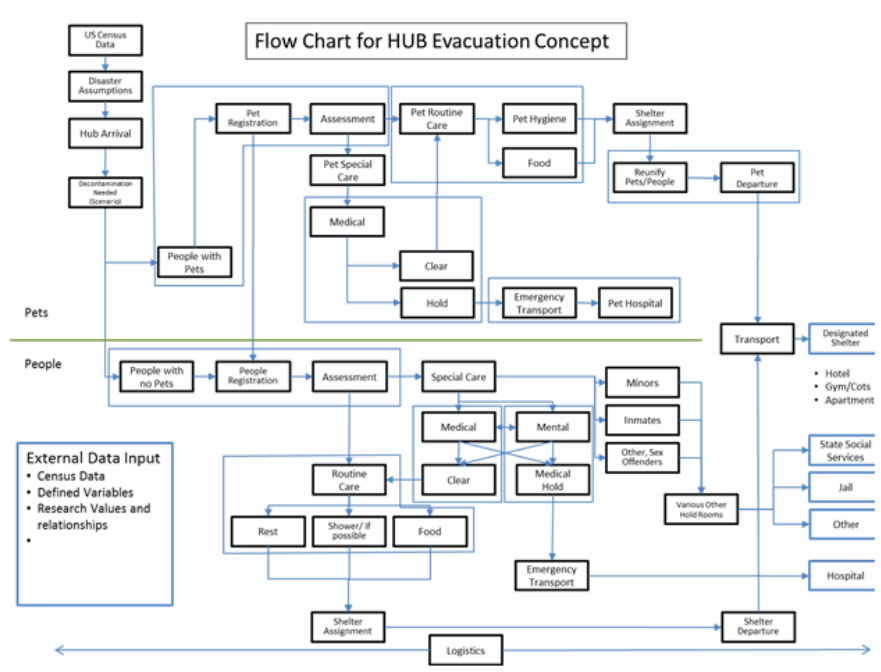

Figure 2. Original flow diagram

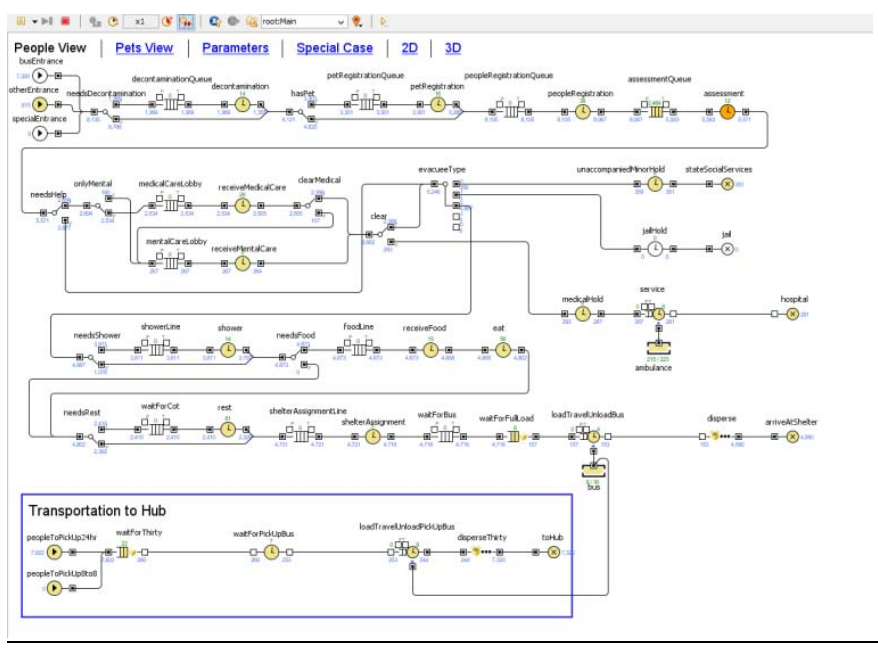

Figure 3. People view

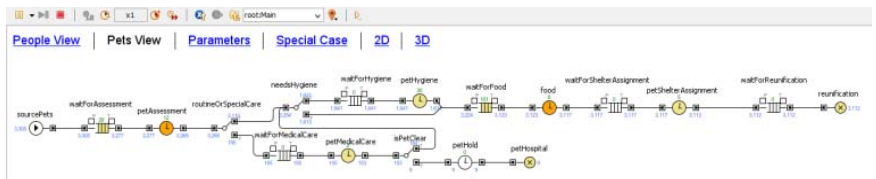

Figure 4. Pets view

\section{MODEL FRAMEWORK}

\subsection{Modeling Tool}

In order to accurately simulate the RHRC, the proper modeling software had to be selected. A piece of software, AnyLogic, was selected as the best option because it provides a very simple way to model the movement of people as agents through various processes. Borshchev, Karpov, and Kharitonov claim that AnyLogic is one of the best pieces of software in the world for agent-based modeling (Borshchev \& Filippov, 2004). Agent-based modeling "captures emergent phenomena," "provides a natural description of a system," and "is flexible" (Bonabeau, 2002). All of these characteristics are found in the RHRC model. AnyLogic's rich libraries allow the user to create a process flow chart for agents to move through. The software is also one of the most widelyused pieces of simulation software by industry and researchers.

AnyLogic provides an optimization tool that uses thirdparty software, called OptQuest. "OptQuest treats the simulation model as a black box; i.e., it observes only the Input/Output (I/O) of the simulation model....OptQuest combines the metaheuristics of Tabu Search, Neural Networks, and Scatter Search into a single search heuristic" (Kleijnen \& Wan, 2007). The OptQuest optimization engine was used in this study to develop accurate amounts of staff for each position in the RHRC depending on the capacity of the facility being used.

\subsection{Independent Variables}

The study consisted of four sets of independent variables. All four were optimized for the best possible throughput. The variables being examined were the probability that a person needs each service provided by the RHRC, the average time needed to complete each process, the number of staff members needed to staff each process, and the amount of space required for the RHRC to function.

\subsection{Sample Set}

The study used roughly 20,000 randomly generated agents for each simulation. Agents were given their own set of probabilities for needing each of the different processes. The agents were generated using a depreciated rate table, which injected, on average, 20,000 agents into the model for each simulation.

\subsection{Testing Methodology}

The model used was a discrete event agent-based model within AnyLogic that represented the flow of an RHRC. The original flow diagram, which was used as the basis for the model, is shown in Figure 2.

The model consisted of six main parts. They are shown in Figures 3 through 8. 


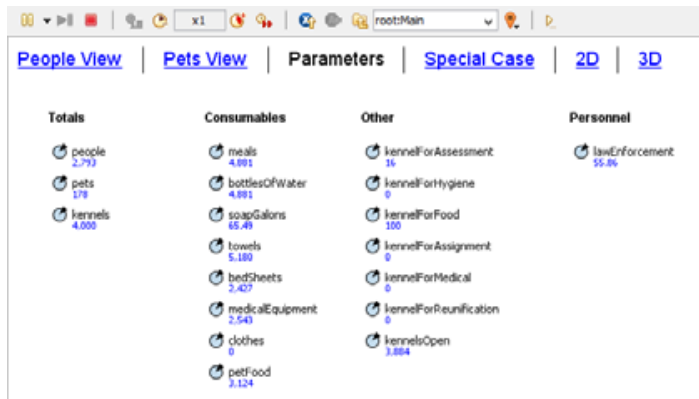

Figure 5. Parameters

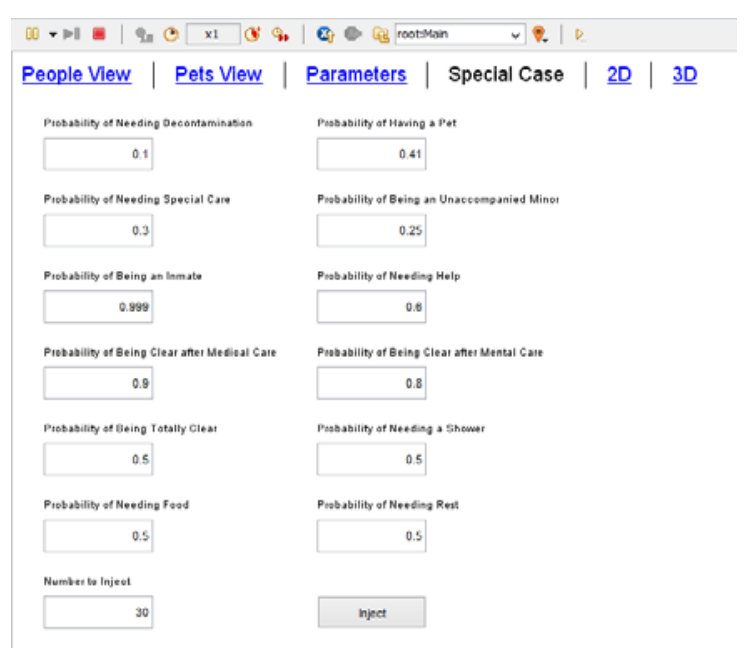

Figure 6. Special case

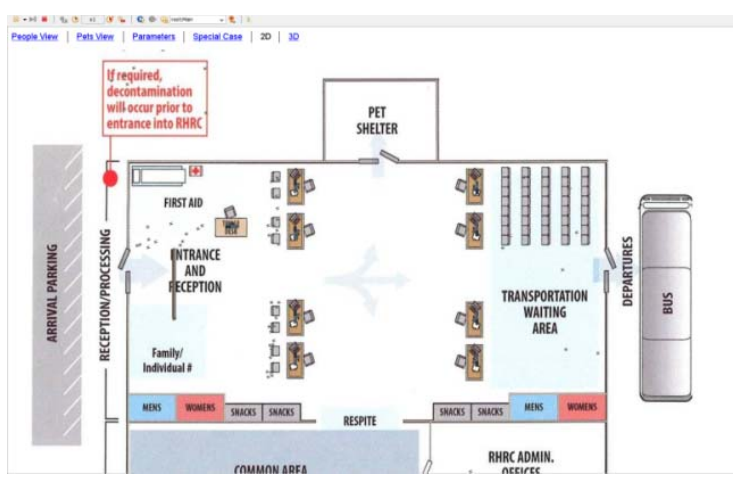

Figure 7. 2-D

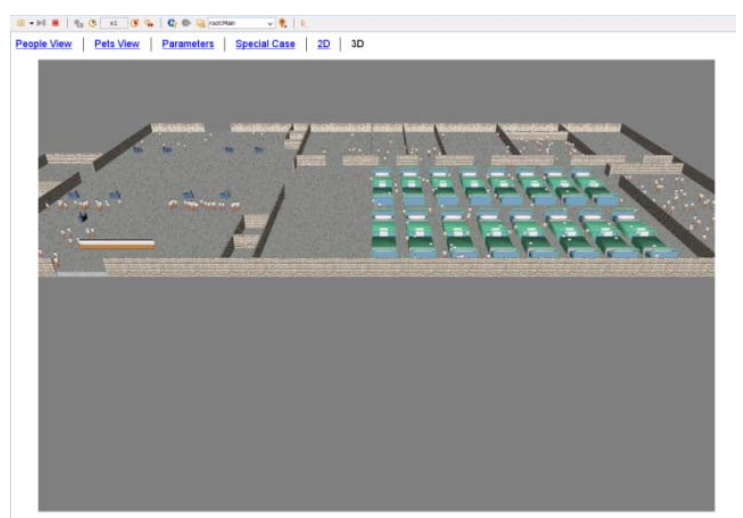

Figure 8. 3-D
The most important parts of the model being studied were Figure 3 and Figure 5. No special cases were injected, pets were ignored for the purposes of the study, and animation had no impact on the results of the model.

To perform a test, the independent variables were tweaked and the model was run. The results were then analyzed to check for changes to the dependent variables, time and resources consumed. Though single simulation runs could show a single set of results, the optimization engine provided by OptQuest allowed for thousands of simulations to be performed for more accurate, average outcomes.

\section{PARAMETERS}

In order to create an accurate representation of an RHRC, research had to be performed to determine the initial values of the static parameters used by the model. The initial parameters remained identical to the parameters used in the previous RHRC study (Table 2).

Table 2. Parameters used

\begin{tabular}{|c|c|c|}
\hline \multirow[b]{2}{*}{ Parameter } & \multicolumn{2}{|r|}{ Details } \\
\hline & $\begin{array}{c}\text { Number } \\
\text { Used }\end{array}$ & Source \\
\hline $\begin{array}{l}\text { Probaility of needing } \\
\text { decontamination }\end{array}$ & 0.167 & $\begin{array}{l}\text { Lake, Fedele, \& } \\
\text { Marshall, } 2000\end{array}$ \\
\hline $\begin{array}{l}\text { Decontamination process } \\
\text { time }\end{array}$ & 576 & Lewis, n.d. \\
\hline Decontamination staff & 20 & $\begin{array}{c}\text { Dietz \& Wojtalewicz, } \\
2012\end{array}$ \\
\hline Probaility of having a pet & 0.41 & $\begin{array}{c}\text { Regional } \\
\text { Catastrophic } \\
\text { Planning Team, } \\
2012 \\
\end{array}$ \\
\hline Pet registration process time & 288 & Lewis, n.d. \\
\hline Pet registration staff & 72 & $\begin{array}{c}\text { Dietz \& Wojtalewicz, } \\
2012\end{array}$ \\
\hline Registration time & 288 & Lewis, n.d. \\
\hline Registration staff & 72 & $\begin{array}{c}\text { Dietz \& Wojtalewicz, } \\
2012 \\
\end{array}$ \\
\hline Assessment time & 288 & Lewis, n.d. \\
\hline Assessment staff & 12 & $\begin{array}{c}\text { Dietz \& Wojtalewicz, } \\
2012\end{array}$ \\
\hline Probability of needing help & 0.47674 & $\begin{array}{l}\text { NIMH, 2012; NIMH, } \\
\text { 2010; CDC, 2012; } \\
\text { Leckie et al., 2005 }\end{array}$ \\
\hline $\begin{array}{l}\text { Probability of only mental } \\
\text { help }\end{array}$ & 0.05317 & $\begin{array}{c}\text { NIMH, 2012; NIMH, } \\
2010\end{array}$ \\
\hline Medical care process time & 1440 & Lewis, n.d. \\
\hline Medical care staff & 60 & $\begin{array}{c}\text { Dietz \& Wojtalewicz, } \\
2012\end{array}$ \\
\hline $\begin{array}{l}\text { Probability of being clear } \\
\text { after medical }\end{array}$ & 0.95626 & $\begin{array}{l}\text { NIMH, 2012; NIMH, } \\
\text { 2010; CDC, 2012; } \\
\text { Leckie et al., 2005 }\end{array}$ \\
\hline Mental care process time & 1440 & Lewis, n.d. \\
\hline Mental care staff & 29 & $\begin{array}{c}\text { Dietz \& Wojtalewicz, } \\
2012\end{array}$ \\
\hline $\begin{array}{l}\text { Probability of being clear } \\
\text { after care }\end{array}$ & 0.8978 & $\begin{array}{c}\text { NIMH, 2012; NIMH, } \\
\text { 2010; CDC, } 2012 \\
\text { Leckie et al., } 2005\end{array}$ \\
\hline $\begin{array}{l}\text { Probability of being an } \\
\text { unaccompanied minor }\end{array}$ & 0.01905 & $\begin{array}{c}\text { Holladay \& } \\
\text { Swanson, } 2010 \\
\end{array}$ \\
\hline
\end{tabular}




\begin{tabular}{|c|c|c|}
\hline \multirow[b]{2}{*}{ Parameter } & \multicolumn{2}{|r|}{ Details } \\
\hline & $\begin{array}{l}\text { Number } \\
\text { Used }\end{array}$ & Source \\
\hline Minor hold process time & 3600 & Lewis, n.d. \\
\hline Minor hold staff & $\max$ & $\begin{array}{c}\text { Dietz \& Wojtalewicz, } \\
2012\end{array}$ \\
\hline $\begin{array}{l}\text { Probability of being an } \\
\text { inmate }\end{array}$ & 0 & estimate \\
\hline Jail hold process time & 5760 & Lewis, n.d. \\
\hline Jail hold staff & $\max$ & $\begin{array}{c}\text { Dietz \& Wojtalewicz, } \\
2012\end{array}$ \\
\hline $\begin{array}{l}\text { Probability of needing a } \\
\text { shower }\end{array}$ & 0.78 & estimate \\
\hline Shower process time & 480 & Lewis, n.d. \\
\hline Shower staff & 36 & $\begin{array}{c}\text { Dietz \& Wojtalewicz, } \\
2012\end{array}$ \\
\hline Probability of needing food & 1 & estimate \\
\hline Receiving food process time & 480 & Lewis, n.d. \\
\hline Food staff & 36 & $\begin{array}{c}\text { Dietz \& Wojtalewicz, } \\
2012\end{array}$ \\
\hline Time to eat & $600-1800$ & estimate \\
\hline Probability of needing rest & 0.5 & estimate \\
\hline Rest process time & $1800-7200$ & estimate \\
\hline Rest staff & 120 & $\begin{array}{c}\text { Dietz \& Wojtalewicz, } \\
2012\end{array}$ \\
\hline $\begin{array}{l}\text { Shelter assignment process } \\
\text { time }\end{array}$ & 115 & Lewis, n.d. \\
\hline Shelter assignment staff & 15 & $\begin{array}{c}\text { Dietz \& Wojtalewicz, } \\
2012 \\
\end{array}$ \\
\hline Aubulances available & 223 & Millen, 2012 \\
\hline Travel to hospital time & 1800 & estimate \\
\hline $\begin{array}{l}\text { Ambulance return to hub } \\
\text { time }\end{array}$ & 1800 & estimate \\
\hline
\end{tabular}

Table 3. Resources

\begin{tabular}{|c|c|c|c|c|c|c|}
\hline \multirow{2}{*}{ Run } & $\begin{array}{c}\text { Meals, } \\
\text { Bottles } \\
\text { of } \\
\text { water }\end{array}$ & $\begin{array}{c}\text { Soap } \\
\text { servin } \\
\text { gs, } \\
\text { towels }\end{array}$ & $\begin{array}{c}\text { Bed } \\
\text { sheets }\end{array}$ & $\begin{array}{c}\text { Medic } \\
\text { al } \\
\text { equip } \\
\text { ment }\end{array}$ & $\begin{array}{c}\text { Cloth } \\
\text { es }\end{array}$ & $\begin{array}{c}\text { Pet } \\
\text { Food }\end{array}$ \\
\hline 1 & 17682 & 17157 & 8775 & 9064 & 3342 & 8142 \\
\hline 2 & 17646 & 17074 & 8838 & 8999 & 3333 & 8148 \\
\hline 3 & 17623 & 17110 & 8861 & 9002 & 3326 & 8077 \\
\hline 4 & 17899 & 17328 & 9102 & 9077 & 3330 & 8225 \\
\hline 5 & 17838 & 17265 & 8970 & 9092 & 3296 & 8338 \\
\hline 6 & 17370 & 16919 & 8732 & 8884 & 3242 & 8018 \\
\hline 7 & 17626 & 17072 & 8885 & 8764 & 3279 & 8046 \\
\hline 8 & 17629 & 17014 & 8780 & 8865 & 3245 & 8021 \\
\hline 9 & 17607 & 16838 & 8806 & 8967 & 3190 & 8166 \\
\hline 10 & 17723 & 17128 & 8974 & 9171 & 3307 & 8248 \\
\hline 11 & 17592 & 17030 & 8741 & 9047 & 3346 & 8095 \\
\hline 12 & 17666 & 17043 & 8859 & 9023 & 3284 & 8230 \\
\hline 13 & 17523 & 17072 & 8710 & 8853 & 3365 & 8007 \\
\hline 14 & 17800 & 17202 & 8978 & 9081 & 3405 & 8245 \\
\hline 15 & 17578 & 17085 & 8813 & 8942 & 3379 & 8111 \\
\hline 16 & 17693 & 16993 & 8724 & 9028 & 3263 & 8036 \\
\hline 17 & 17867 & 17466 & 8813 & 9108 & 3471 & 8152 \\
\hline 18 & 17716 & 17189 & 8790 & 9083 & 3336 & 8292 \\
\hline 19 & 17797 & 17295 & 8920 & 9126 & 3385 & 8351 \\
\hline 20 & 17807 & 17169 & 8858 & 9054 & 3382 & 8294 \\
\hline 21 & 17459 & 16871 & 8740 & 8862 & 3323 & 8078 \\
\hline 22 & 17463 & 16882 & 8740 & 8952 & 3294 & 8047 \\
\hline 23 & 17748 & 17119 & 8774 & 8987 & 3281 & 8123 \\
\hline 24 & 17757 & 17147 & 8748 & 9050 & 3328 & 8189 \\
\hline 25 & 17552 & 16959 & 8732 & 8968 & 3272 & 8068 \\
\hline Avg & 17666 & 17097 & 8827 & 9002 & 3320 & 8150 \\
\hline & & & & & & \\
\hline
\end{tabular}

Certain parameters were undeterminable because they would depend on the specific facility being used. For those parameters, reasonable estimates were used. Processes such as eating and resting required a random amount of time for each individual.

\section{MATERIALS}

The first optimization problem performed in the study was to determine the amount of materials consumed over the 7-day period. The materials being examined were meals, bottles of water, soap, towels, bed sheets, medical equipment, clothes, and pet food. Though other materials may be used, the eight selected in the study were chosen as a proof of concept that the model could accurately determine the amount required of any resource.

The results were calculated using 25 model runs. Each run calculated the specific amount of each resource consumed. After the completion of the 25 runs, the results were averaged for an accurate result. The data is shown in Table 3.

\section{STAFF AND SPACE}

Determining the number of staff required to staff each position in the RHRC required extensive use of OptQuest. Each process was assumed to use a oneto-one ratio for staff and evacuees while each evacuee completed a process. The service positions being optimized in the study were decontamination, pet registration, people registration, assessment, medical care, metal care, food services, and shelter assignment. Each service could have no less than 1 and no more than 100 staff members. It is important 
to note that performing every possible combination of staff members would require $100^{8}$ $(10,000,000,000,000,000)$ simulations. That many simulations would be impossible. Therefore, the optimal solution found by the study is not the only optimal solution. It is, however, the optimal solution of the 1,000 simulation runs for each sample. Ten total staff quantities were tested, ranging from 50 to 500 . Once an optimal staff quantity was found, further testing was performed to ensure that the result was not a local optimum.

The model also required a threshold to be set for the occupancy of the RHRC. This was to determine the optimal size of a facility along with the optimal number of staff it could accommodate. Once finding the optimal solution, the quantities were passed back into the model and tested for average individual throughput time and total operation time of the RHRC. The results of the optimization for staff are discussed in the following section.

Depending on the number of staff on duty, the RHRC can keep the number of evacuees below a certain threshold. The results are shown in Table 4. Subtracting the staff amount from the max occupancy determines the maximum number of evacuees in the $\mathrm{RHRC}$ at any one time given the staff amount.

\section{RESULTS}

Calculating the final results required 89,000 simulation runs. Depending on the number of staff, total operation time ranged from 6.89 days to 8.00 days. Increasing staff from 50 to 300 decreased total operation time. Increasing staff beyond 300 did not decrease total operation time. However, as can be seen from the results in Figure 9, altering total staff had very little effect on total operation time. This is because the model ended when the last evacuee exited the facility, and evacuees were allowed to enter up until the end of day seven.

Like total operation time, average individual throughput time as a function of staff yielded improvements when staff was increased. These improvements leveled off at 250 total staff members who were able to process evacuees in 5.65 hours on average. The results are shown in Figure 10. Increasing total staff beyond 250 yielded minimal improvement to average individual throughput time.

Total occupancy was also improved by increasing the number of total staff. Once again, the curve leveled off at 250 total staff members. The results are shown in Figure 11. The number of evacuees in the facility could not be kept below 1,900 with any number of staff. Additional staff after 250 only increased the total occupancy of the facility by adding to the 1,900 evacuees.
Table 4. Space

\begin{tabular}{|c|c|}
\hline Staff Amount & Max Occupancy \\
\hline 500 & 2400 \\
\hline 450 & 2350 \\
\hline 400 & 2400 \\
\hline 350 & 2350 \\
\hline 300 & 2600 \\
\hline 250 & 2250 \\
\hline 200 & 3400 \\
\hline 150 & 5150 \\
\hline 100 & 7800 \\
\hline 50 & $\mathrm{n} / \mathrm{a}$ \\
\hline
\end{tabular}

\section{Total Operation Time}

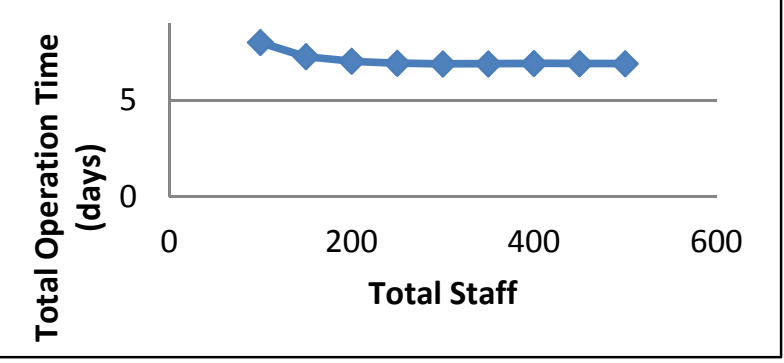

Figure 9. Total operation time

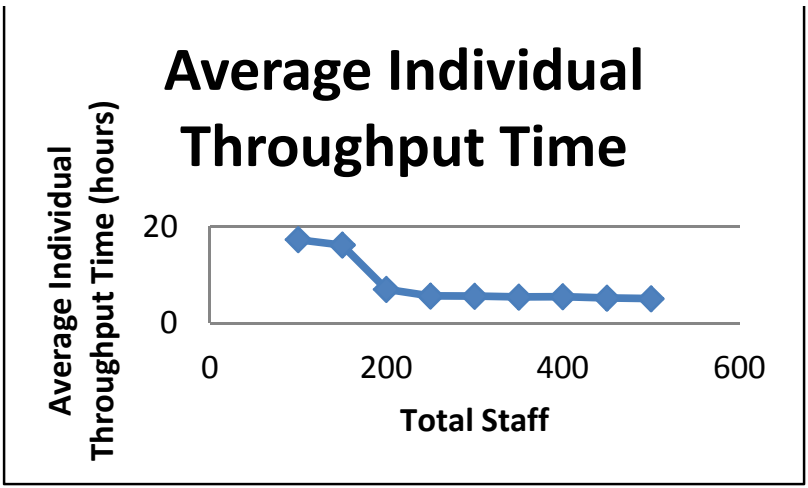

Figure 10. Average individual throughput time

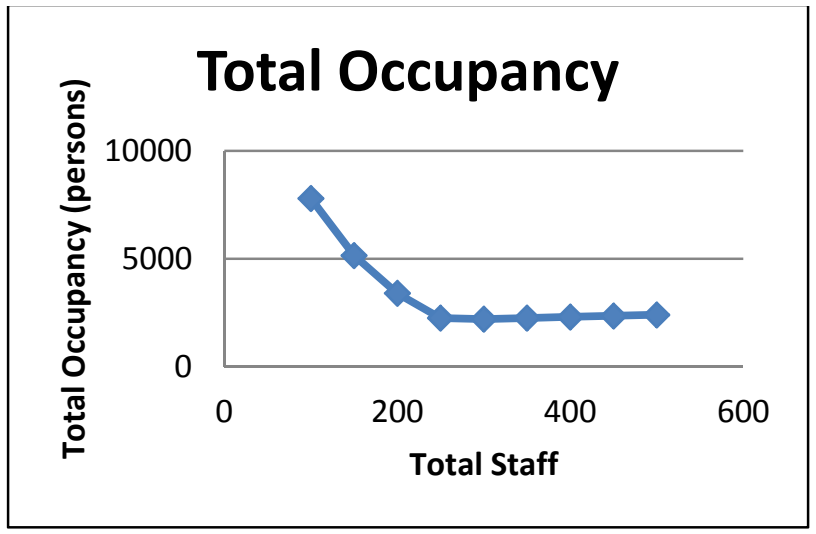

Figure 11. Total occupancy 


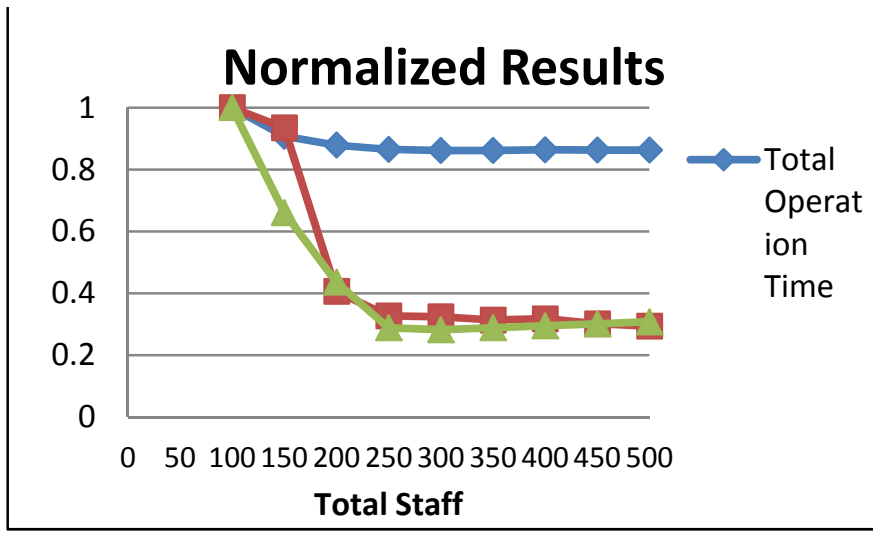

Figure 12. Combined results

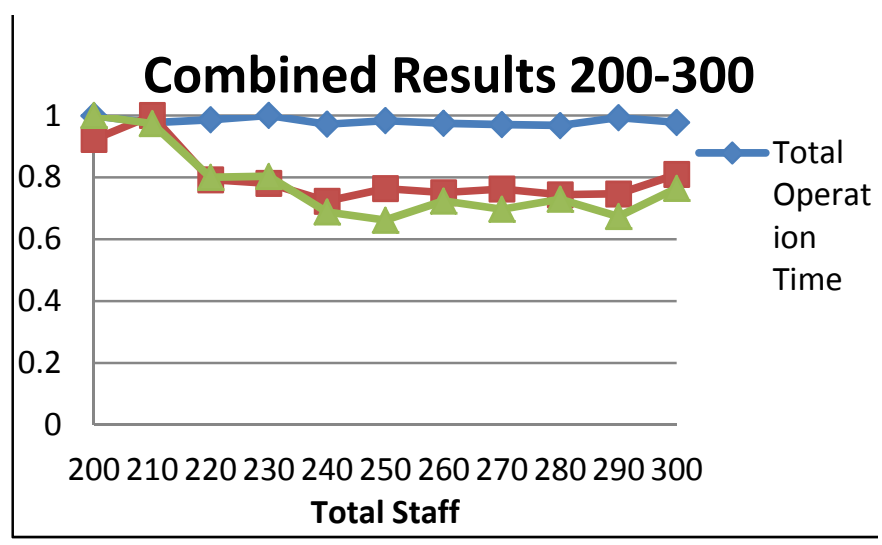

Figure 13. Combined results $200-300$

Figure 12 shows the combined results of all three plots on one graph.

In order to ensure that 250 total staff was not a local optimum, further testing was performed on the interval of 200 to 300 total staff. The results, shown in Figure 13, confirm that a value between 240 and 250 total staff members is optimal.

\section{CONCLUSION}

The study confirmed that optimizing staff, materials, space, and time required to operate an RHRC for 20,000 evacuees over its entire 7-day duration greatly depends on the number of total staff available. A staff of 250 total members was ideal in all three areas being studied. Therefore, 250 total staff can be considered optimal to operate an RHRC.

The results of the study show that the original estimates of the Regional Catastrophic Planning Team could be improved. The team's estimate of 316 total staff for the eight positions can be decreased to 250. At 250 total staff, the RHRC can process all of the individuals in 6.92 days, which is an improvement over the team's goal of 7 days. Also, each individual can be processed in less than 6 hours, which is less than $25 \%$ of the team's goal of 24 hours.
A facility large enough to hold 2,250 persons would be large enough for this RHRC to function. The improved efficiency can also be measured financially. Assuming staff members work 12-hour shifts and are paid $\$ 200$ daily, the improvements to the team's initial estimates would save $\$ 184,000$. Even greater savings are reached due to less training required and less resources consumed.

Further research should be performed to test the efficiency of multiple RHRCs. More research can also be done to test for a more accurate result for financial savings. Lastly, another study could be performed to determine if 20,000 evacuees should be the processing goal for each RHRC. This research, however, demonstrated that the goals set forth by the Regional Catastrophic Planning Team can be met and further optimized. Such optimization ensures that the facility is able to improve the resiliency of a major city if a catastrophic event is to occur.

\section{REFERENCES}

Bonabeau, E. (2002). Agent-based modeling: Methods and techniques for simulating human systems. National Academy of Sciences of the United States of America, 99(3).

Borshchev, A. \& Filippov, A. (2004). From system dynamics and discrete event to practical agent based modeling: Reasons, techniques, tools. Proceedings of the 22nd International Conference of the System Dynamics Society, Oxford, England.

Centers for Disease Control and Prevention. (2012). Summary statistics for U.S. adults: National health interview survey, 2010. Vital and Health Statistics, 10(252).

Dietz, J. E., \& Wojtalewicz, C. (2012). Regional Hub Reception Center Project. West Lafayette, IN: Purdue Homeland Security Institute.

Holladay, J., \& Swanson, L. (2010). 2010 Report to the President and Congress (AHRQ Publication No. 10-M037). Rockville, MD: Agency for Healthcare Research and Quality. Retrieved from http://www. childrenanddisasters.acf.hhs.gov

Kirby, A., Dietz, J. E., \&Wojtalewicz, C. (2012). Modeling of a regional hub reception center to improve the speed of an urban area evacuation. Proceedings of the 2012 IEEE Conference on Technologies for Homeland Security (pp. 476-482). http://dx.doi.org/10.1109/THS.2012.6459895

Kleijnen, J. P. C., \& Wan, J. (2007). Optimization of simulated systems: OptQuest and alternatives. Simulation Modelling Practice and Theory, 15(3), 354-362. http://dx.doi.org/10.1016/j.simpat. 2006.11.001

Lake, W. A., Fedele, P. D., \& Marshall, S. M. (2000, January). Guidelines for mass casualty decontamination during a terrorist chemical agent 
incident [PDF]. APG, MD: U.S. Army Soldier and Biological Chemical Command (SBCCOM).

Retrieved from https://www.ecbc.army.mil/ downloads/cwirp/ECBC_cwirp_gls_mass_casualty_ decon.pdf

Leckie, A. M., Graham, M. K., Grant, J. B., Ritchie, P. J., \& Frier, B. M. (2005). Frequency, severity, and morbidity of hypoglycemia occurring in the workplace in people insulin-treated diabetes. Diabetes Care, 28(6), 1333-1338. http://dx.doi. org/10.2337/diacare.28.6.1333

Lewis, J. (n.d.). Logistics: Staffing with the RHRC model. Unpublished manuscript.

Milen, D. personal communication, April 13, 2012.

National Institute of Mental Health. (2010). Suicide in the U.S.: Statistics and prevention (Publication No. 06-4594). Bethesda, MD: National Institute of Mental Health. Retrieved from http://www.nimh.nih. gov/health/publications/suicide-in-the-us-statisticsand-prevention/index.shtml
National Institute of Mental Health. (2012). [Graph chart explanation of percentage of adults with a severe mental illness]. Prevalence of Serious Mental IIIness Among U.S. Adults (2012). Retrieved from http://www.nimh.nih.gov/statistics/SMI_AASR.shtml

Regional Catastrophic Planning Team. (2012). Regional hub reception center operational guidance document. Chicago, IL: City of Chicago Office of Emergency Management and Communication.

Renne, J. L., Sanchez, T. W., Jenkins, P., \& Peterson, R. (2009). Challenge of evacuating the carless in five major U.S. cities. Transportation Research Record: Journal of the Transportation Research Board, 2119, 36-44. http://dx.doi.org/10.3141/2119-05

Waselenko, J. K., MacVittie, T. J., Blakely, W. F., Pesik, N., Wiley, A. L., Dickerson, W. E.,...Dainiak, N. (2004, June 15). Medical management of the acute radiation syndrome: Recommendations of the Strategic National Stockpile Radiation Working Group. Annals of Internal Medicine, 140(12), 10371051. http://dx.doi.org/10.7326/0003-4819-140-12200406150-00015 